\title{
Role of Partial Thoracoplasty in Lung Lesions -A Single Institute Experience
}

\author{
Binay Krishna Sarkar*, Krishnendu Chakraborty, Pares Bandyopadhayay \\ Department of Cardiovascular \& Thoracic surgery, Nil Ratan Sircar Medical College \& Hospital, Kolkata, West Bengal, India \\ Email: ^bappa_2k1_bk@yahoo.co.in
}

How to cite this paper: Sarkar, B.K., Chakraborty, K. and Bandyopadhayay, P. (2019) Role of Partial Thoracoplasty in Lung Lesions-A Single Institute Experience. World Journal of Cardiovascular Surgery, 9, 155-162. https://doi.org/10.4236/wjcs.2019.911017

Received: June 11, 2019

Accepted: November 19, 2019

Published: November 22, 2019

Copyright $\odot 2019$ by author(s) and Scientific Research Publishing Inc. This work is licensed under the Creative Commons Attribution International License (CC BY 4.0).

http://creativecommons.org/licenses/by/4.0/

(c) (i) Open Access

\begin{abstract}
Thoracoplasty has been a useful procedure to control and cure recalcitrant lung lesions often as a last measure to treat pulmonary infections like posttubercular chronic empyema with fibrocavitary lesions and residual pleural space infections after pulmonary resections. Long-standing empyemas with persistent discharge on drainage often respond poorly after decortication and debridement alone due to non-expanding underlying lung tissue due to fibrotic changes. These cases often develop recurrent empyemas with sepsis with high morbidity and mortality. Similarly chronic space-occupying lung lesions with adjacent pulmonary damage and fibrosis leave a considerable residual space after surgery of these lesions and these persistent residual space leads to pleural space infections and empyema. In the presence of a large apical abscess and destruction of the apical pulmonary tissue forming a potential space confined by the bony thoracic cage and limited inferiorly by the rigid lining of the abscess, the cure and management of the chronic empyema especially the post-tubercular ones are particularly difficult. We address these cases in our series by performing partial thoracoplasty tailored to the site of the lesions in addition to other procedures. Partial thoracoplasty was found beneficial for selective cases of chronic empyema, obliteration of residual cavity after resectional surgery and management of the apical abscess.
\end{abstract}

\section{Keywords}

Partial Thoracoplasty, Chronic Empyema, Residual Pleural Space Infection, Apical Lung Abscess

\section{Introduction}

Thoracoplasty was popularised mainly as a method of lung collapse by removal of the skeletal support of a portion of chest wall to achieve healing of tuberculo- 
sis before the introduction of antitubercular drugs [1] [2] [3] [4]. It was largely abandoned due to its mutilating nature, deformity, shoulder and hand dysfunction and poor toleration. It became obsolete after the advent of modern chemotherapy for tuberculosis and Thoracic Surgeons became less interested in thoracoplasty due to development of more conventional, less mutilating and more effective pulmonary procedures.

However, effective treatments of chronic empyema often pose a difficult management problem for Cardiothoracic Surgeons due to unrelenting pleural space infection, recurrence after surgery and attended morbidity and mortality [4] [5] [6]. A series of thoracic operations may be necessary to control the chronic intrathoracic suppuration. Long standing empyemas with persistent discharge on drainage often respond poorly after decortication and debridement alone due to non-expanding underlying lung tissue due to fibrotic changes. These cases often develop recurrent empyemas with sepsis with high morbidity and mortality. Similarly chronic space occupying lung lesions with adjacent pulmonary damage and fibrosis leave a considerable residual space after surgery of these lesions and these persistent residual space leads to pleural space infections and empyema. In the presence of a large apical abscess and destruction of the apical pulmonary tissue forming a potential space confined by the bony thoracic cage and limited inferiorly by the rigid lining of the abscess, management of the chronic empyema especially the post-tubercular ones are particularly difficult. Partial thoracoplasty was found beneficial for selective cases of chronic empyema, obliteration of residual cavity after resectional surgery and displacement of the apical abscess.

\section{Methods}

Since July, 2008 till September, 2018, 36 patients (mean age, 46 years, age range from 19 years to 72 years; with 27 male and 9 female patients; male:female $=3: 1$ ) underwent partial thoracoplasty in our institute in the department of Cardiovascular and Thoracic Surgery, NRS Medical College \& Hospital, Kolkata, West Bengal, India. These cases were retrospectively studied. Cases with unilateral or bilateral diffuse fibro cavitary disease were excluded from the study. Preoperatively all patients had standard preoperative preparation. Computed tomography and pulmonaty function studies were done routinely in all cases. Computed tomography was particularly important to locate the precise site of empyema, its depth, position drains, relation of visceral pleura with parenchyma.

A double-lumen endotracheal tube was used in all cases. A standard posterolateral thoracotomy was made and the empyema cavity was opened or the site of intrapleral lesion was explored. Assessment was made to determine the number of ribs to be resected and complete excision of the ribs were made. Plication sutures were applied and intercostal muscles with neurovascular bundle, periosteum with thickened parietal pleura were allowed to dip into the cavity to obliterate it. 


\section{Result}

Twenty two patients had post tubercular empyaema, nine patients had bronchiectasis, three cases had aspergilloma and two patients had neoplastic lung disease.

Partial thoracoplasty (Figure 1(a) and Figure 1(b)) was done in all these cases in addition to other procedures like decortication, debridement, pulmonary wedge resection, excision of benign cystic neoplasm, upper and lower lobectomy (Table 1). Video assistance was utilised as and when necessary. Partial thoracoplasty was done in all cases with subperiosteal excision of 3 to 5 ribs (mean 3.9 ribs) overlying pleural or pleuro-pulmonary cavities and residual spaces along with other procedures as a single stage procedure. First rib was spared in all cases. Mean intraoperative blood loss during was 400 to $500 \mathrm{ml}$. Prolonged air leaks were not seen.

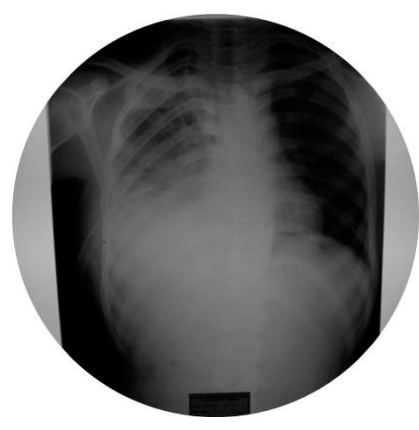

(a)

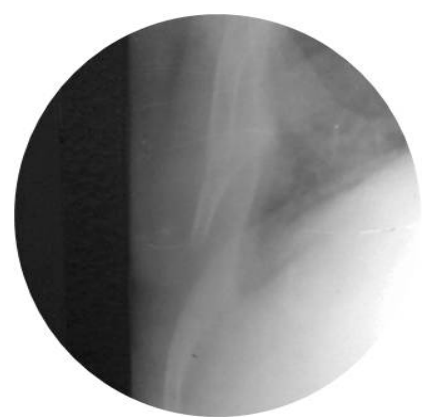

(b)

Figure 1. (a) preop chest x-ray of right sided empyema; (b) showing postop chest x-ray after right lower partial thoacoplasty.

Table 1. Shows demographic data and patient characteristics.

\begin{tabular}{|c|c|c|}
\hline Character (n) & $\mathrm{n}=27$ & $\mathrm{n}=9$ \\
\hline Sex & male & female \\
\hline Age (mean in years) & $\begin{array}{l}\text { Range: } 19 \text { years to } \\
72 \text { years }(62.5)\end{array}$ & $\begin{array}{c}\text { Range: } 21 \text { years to } \\
64 \text { years }(45.5)\end{array}$ \\
\hline \multicolumn{3}{|l|}{ Disease involved } \\
\hline 1) Post tubercular empyema & 16 & 6 \\
\hline $\begin{array}{l}\text { 2) Bronchiectasis and } \\
\text { postpneumonic empyema }\end{array}$ & 6 & 3 \\
\hline 3) Neoplastic (cystic) & 2 & \\
\hline 4) Aspergilloma & 3 & \\
\hline \multicolumn{3}{|l|}{ Site of thoracoplasty } \\
\hline Rt upper (apicolysis) & $9(5)$ & $3(2)$ \\
\hline Rt lower & 13 & 4 \\
\hline Left upper & 2 & 0 \\
\hline Left lower & 3 & 2 \\
\hline Investigation (pre-op) & $\begin{array}{r}\text { Routine hematologic } \\
\text { Chest x-ray, } \\
\text { Pulmo }\end{array}$ & $\begin{array}{l}\text { nemical examination } \\
\text { nography Scan, } \\
\text { Test }\end{array}$ \\
\hline
\end{tabular}


In case of chronic empyema, subperiosteal removal of ribs overlying the empyema cavity was done after entering the suppurated pleural cavity with careful removal of the pus and devitalised tissue. After muscle and skin apposition, temporary fixation of the chest wall using compressive bandage and an external support helped maintaining collapsed position and in reducing post-operative pain. This allows a definitive fixation of the new chest wall in a more natural position and the patient starts to breathe normally.

Two of our elderly male patients had long standing large benign cystic neoplasms (Figure 2(a) and Figure 2(b)) and three patients of aspergilloma with compressed and fibrosed surrounding lung tissue and limited thoracoplasty was required to address the redundant cavity.

Out of twelve upper partial thoracoplasty, seven cases required apicolysis.

All patients were extubated postoperatively and none of them required postop ventilatory support. Postoperative surveillance with CXR was done in all cases. Degree of air leak, nature and duration of drainage and wound infection were noted post-operatively. All these cases had primary wound healing without any wound dehiscence.

There were minor wound infection and delayed healing in few cases (3/36) (Table 2). Operative mortality was nil. Average hospital stay was 7 days in males and 7.5 days in females. Patients were followed up with a maximum follow up of 8 years. Patients had acceptable physical appearance (Figure 3 ) and reasonably good quality of life.

\section{Discussion}

Thoracoplasty was first introduced by Estlander (1879) who performed resection of multiple fragments of ribs to achieve obliteration of an underlying empyema [2] [3]. It targets the resolution of a pleural or pulmonary cavity by collapsing the chest wall through rib resection, excising 8 - 9 ribs. Ribs can be excised extra-periosteally or sub-periosteally [4] [5] [6] [7]. Depending on the violation of

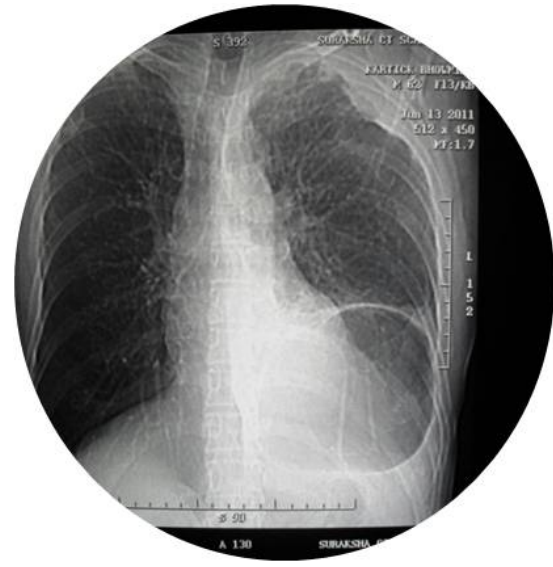

(a)

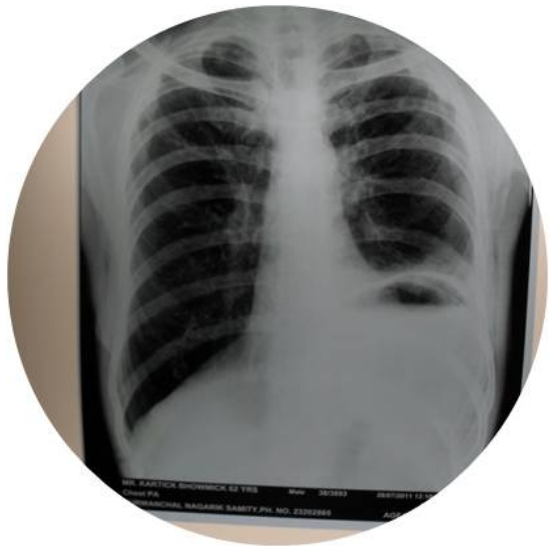

(b)

Figure 2. (a) preop chest x-ray showing large cystic lesion in left lower chest; (b) showing postop chest $\mathrm{X}$-ray after left lower partial thoracoplasty. 


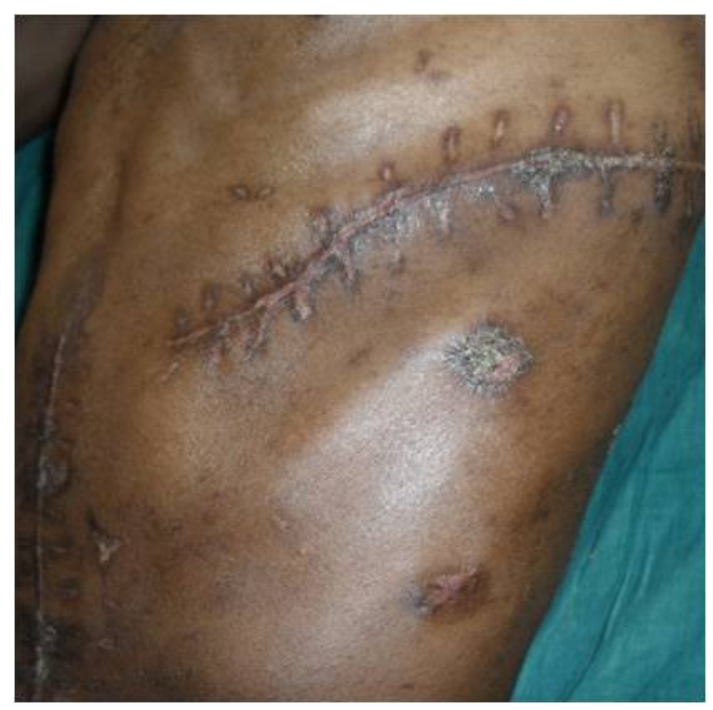

Figure 3. Showing minimal chest deformity after partial thoracoplasty (postopative day $10)$.

Table 2. Shows post-operative results.

\begin{tabular}{ccc}
\hline $\mathbf{n}=\mathbf{3 6}$ & Male ( $\mathbf{n}=\mathbf{2 7})$ & Female $(\mathbf{n}=\mathbf{9})$ \\
\hline Procedures & & \\
1) Lobectomy & $7(25.9 \%)$ & $2(22.2 \%)$ \\
2) Wedge excision & $10(37 \%)$ & $3(33.3 \%)$ \\
3) Decortication & $16(59.2 \%)$ & $6(25.9 \%)$ \\
4) Excision of cyst & $2(7.4 \%)$ & $1(11 \%)$ \\
Wound infection & $2(7.4 \%)$ & $1(11 \%)$ \\
Air leak (up to 3 days) & $5(18.5 \%)$ & $7-10(7.5)$ \\
\hline
\end{tabular}

the pleura, it can be intra or extrapleural. It can be performed through single or multiple stages. Many surgeons preferred to perform the thoracoplasty in multiple stages, resecting 2 - 3 ribs in each step to lower the magnitude of morbidity and mortality [2]. But it could be problematic when there is cavity movement phenomenon without resolution of cavity.

In the past, the pleural space was not opened to avoid wound contamination, pneumothorax etc during thoracoplasty. Opening the pleura can give direct access to address the pleural/or pulmonary lesion and allows decortication and dedridement [8]. Subperiosteal rib excision is beneficial for long term stabilisation of chest wall.

This tailored procedure was found suitable in elderly diabetic with compromised lung function. Procedure was performed uneventfully and recovery was faster without much morbidity. After eradication of source of infection, these cases did fairly well in terms of control of diabetes Mellitus, breathlessness and working capacity. 
Video assistence (VATS) was done for initial assessment and release of adhesions. This was particularly useful in exploration of apical region, decorticate remote areas, debridement and hemostasis under vision.

Effective treatment of chronic empyema often pose a difficult management problem for Cardiothoracic Surgeons due to unrelenting pleural space infection, recurrence after surgery and attended morbidity and mortality. Series of thoracic operations may be necessary to control the chronic intrathoracic suppuration. In selected cases of chronic empyema after decortication with or without resectional surgery, when a cavity persists and occupies a part of the hemithorax after lung inflation and release of pulmonary adhesions, a limited thoracoplasty was found beneficial for obliteration of residual cavity and displacement of the apical abscess. In many cases ribs overlying the empyema cavity were found to be ostomyelitic and it is beneficial to remove ostomyelitic ribs in long standing empyema with intercostal chest drain.

Even in absence of empyema in two of our cases, after removal of large cystic neoplasm from the lung, the cavity was found considerably large after adhesionolysis and lung inflation. Ipsilateral lung was found fibrotic. Similarly in three cases of aspergilloma after lobectomy partial thoracoplasty was done to tailor the thoracic cavity as the remaining lung had limited capacity to expand due to long standing inflammation and fibrosis. Considering remote possibility of obliteration of cavity by compensatory changes and subsequent infective complication, limited thoracoplasty was done to obliterate cavity with excellent result.

Operative morbidity was less, recovery was rapid, deformity was minimal and there was no recurrence. Stefani et al. had also shown that partial thoracoplasty was effective both when used in isolation and when combined with other procedures to fill the residual cavity [7].

Althogh several Surgeons [6] [8] [9] stressed the importance of myoplasty to fill the cavity over thoracoplasty due to resulting chest deformity, this is a major procedure requiring good muscle flap, multiple procedures and often associated with infection in malnourished patient.

In case of a large apical abscess following destruction of the apical pulmonary tissue and continuous suppurating infection in post tubercular cases or in chronic suppuration, a potential space is formed, surrounded by the bony thorax and limited inferiorly by the rigid lining of the abscess. The lower limit of the abscess may be so rigid due to progressive deposition of fibrous tissue along with tough adhesions, filling the gap by healthy expanding lung is not possible [2]. Limited thoracoplasty along with apicolysis by dividing adhesions between the pleural dome at the apex and the soft tissues from the base of the neck, was effective in resolution of the unrelenting apical abscess. Apycolysis was introduced by Semb (1937) and done by releasing the adhesions between the apical pleura and the soft tissues from the base of the neck. This technique was particularly beneficial in post-tubercular apical lung abscess to achieve more complete collapse of the lung apex. First rib resection was not attempted in our series as its 
resection is associated with scoliosis, asymmetry and functional impairment of the shoulder and upper limb. We found that apicolysis without sacrificing first rib was adequate to achieve resolution of cavities.

Moreover, in presence of bilateral lung disease or generalised disease it is imperative to preserve as much lung as possible when vital capacity is already low and partial thoracoplasty is more desirable than more radical complete thoracoplasty or further pulmonary resections [10] [11] [12].

Deslauriers and colleagues [8] pointed out that patient selection is very important to achieve the goal of healed chest wall and eradication of infection. This minimal technique is also beneficial for patients with poor nutrition and other co-morbidities.

\section{Conclusion}

We conclude that addition of Partial thoracoplasty may provide a one-stage cure with lung preservation avoiding the hazards of prolonged infection, debility and avoids unnecessary pneumonectomies in selected patients. The remaining lung may preserve the respiratory function and resolve the additional space problem.

\section{Conflicts of Interest}

The authors declare no conflicts of interest regarding the publication of this paper.

\section{References}

[1] Daly, R.C., Pairolero, P.C., Piehler, J.M., Trastek, V.F., Spencer Payne, W. and Berenatz, P.E. (1986) Pulmonary Aspergilloma. The Journal of Thoracic and Cardiovascular Surgery, 92, 981-988.

[2] Holman, E. and Pierson, P. (1938) Selective Collapse by Partial Thoracoplasty: Recent Advances in the Surgical Treatment of Pulmonary Tuberculosis. California and Western Medicine, 48, 312-317.

[3] Decamp, P.T. and Acree, P.W. (1954) Suture Ligation of the Lung and Partial Thoracoplasty in the Treatment of Tuberculosis; A Four-Year Experience. American Review of Tuberculosis, 70, 61-70.

[4] Peppas, G., Molnar, T.F., Jeyasingham, K. and Kirk, A.B. (1993) Thoracoplasty in the Context of Current Surgical Practice. The American Review of Tuberculosis, 56, 903-909. https://doi.org/10.1016/0003-4975(93)90353-J

[5] Okumura, Y., Takeda, S., Asada, H., Inoue, M., Sawabata, N., Shiono, H. and Maeda, H. (2005) Surgical Results for Chronic Empyema Using Omental Pedicled Flap: Long-Term Follow-up Study. The Annals of Thoracic Surgery, 79, 1857-1861. https://doi.org/10.1016/j.athoracsur.2005.01.001

[6] Laisaar, T. and Ilves, A. (1997) Omentoplasty Together with Partial Thoracoplasty: A One-Stage Operation for Postpneumonectomy Pleural Empyema. Annales Chirurgiae et Gynaecologiae, 86, 319-324.

[7] Stefani, A., Jouni, R., Alifano, M., Bobbio, A., Strano, S., Magdeleinat, P. and Regnard, J.F. (2011) Thoracoplasty in the Current Practice of Thoracic Surgery: A Single-Institution 10-Year Experience. The Annals of Thoracic Surgery, 91, 263-268. https://doi.org/10.1016/j.athoracsur.2010.07.084 
[8] Deslauriers, J., Jacques, L.F. and Gregoire, J. (2001) Role of Eloesser Flap and Thoracoplasty in the Third Millennium. Chest Surgery Clinics of North America, 12, 605-623. https://doi.org/10.1016/S1052-3359(02)00017-0

[9] Krassas, A., Grima, R., Bagan, P., Badia, A., Arame, A., Barthes Fle, P. and Riquet, M. (2010) Current Indications and Results for Thoracoplasty and Intrathoracic Muscle Transposition. European Journal of Cardio-Thoracic Surgery, 37, 1215-1220. https://doi.org/10.1016/j.ejcts.2009.11.049

[10] Laisaar, T. and Ilves, A. (1999) Surgical Treatment of Pleural Empyema-Changing Priorities. Scandinavian Cardiovascular Journal, 33, 97-102. https://doi.org/10.1080/14017439950141902

[11] Hopkins, R.A., Ungerleider, R.M., Staub, E.W. and Young Jr., W.G. (1985) The Modern Use of Thoracoplasty. The Annals of Thoracic Surgery, 40, 181-187. https://doi.org/10.1016/S0003-4975(10)60016-1

[12] Molnar, T.F. (2007) Current Surgical Treatment of Thoracic Empyema in Adults. European Journal of Cardio-Thoracic Surgery, 32, 422-430.

https://doi.org/10.1016/j.ejcts.2007.05.028 